\title{
Baseline Natural Radiation Level Survey of Iuleha Clan in Owan-West Local Government Area Edo State
}

\author{
1*EJERE, AII; ${ }^{2}$ ELOHOR, OR; ${ }^{3}$ OSAGIE, UO \\ ${ }^{*}$ Department of Physics, Faculty of Physical Sciences, University of Benin, Benin City, Nigeria. \\ ${ }^{2}$ Department of Physics, Faculty of Sciences, University of Port Harcourt, Choba, Rivers state, Nigeria. \\ ${ }^{3}$ Edo State Institute of Technology and Management, Usen, Edo State Nigeria. \\ *Corresponding Author Email: ejere.arthur@uniben.edu, rolioloko@yahoo.com, usmanosagie@gmail.com
}

\begin{abstract}
Investigation of ambient radiation level of Iuleha clan in Owan - West Local Government Area, Edo State has been carried out using the radiation meter Digilert 50, Nuclear Radiation Monitor. The background natural radiation level Count per hour ( $\mathrm{Cph}$ ) of eighteen sites of the total expanse of the clan were measured. The $\mathrm{Cph}$ values ranged from $848 \mu \mathrm{Sv} / \mathrm{hr}$ (Aoma market) to $1308.00 \mu \mathrm{Sv} / \mathrm{hr}$ (Okagboro). It was discovered that sites with high Cph were close to granite deposit or had granite subsurface foundation.
\end{abstract}

\section{DOI: https://dx.doi.org/10.4314/jasem.v22i7.9}

Copyright: Copyright $\left({ }^{(C)} 2018\right.$ Ejere et al. This is an open access article distributed under the Creative Commons Attribution License (CCL), which permits unrestricted use, distribution, and reproduction in any medium, provided the original work is properly cited.

Dates: Received: 30 March 2018; Revised: 06 May: 2018; Accepted: 02 June 2018

Keywords: Radiation level; Natural radioactivities; Ionizing radiation; Radiation pollution.

Knowledge of the natural background radiation of our environment is of critical importance for correct assessment of radiation pollution. Man's environment is constantly exposed to radiation whether he is aware of it or not. Background radiation of the environment consist of cosmic rays and radiation emitted from radioactive substance present in the ground air food and drinking water and commercial sources (NCRP, 1976). All living organism have being exposed to background radiation since their appearance on Earth (Prasad et al., 2004). Natural radioactivity is present in the environment right from the time of formation of the universe and it played a great role in the evolution of all components living and non-living of earth as we see it today (Daryoush et al., 2013).

The effective does of ionizing radiation on man depend on some factors such as special position of living, occupation, personal habits, diet, building type and house utilization pattern (Malathi et al., 2005). IAEA (1986) estimated that $85 \%$ of radiation dose received by man are derived from natural radioactivities in the environment, while the remaining $15 \%$ are from cosmic rays and artificial sources such as nuclear processes, industrial waste and effluent from factories.

Farai and Jibiri (2000) did out door gamma radiation level measurement. Some concerned scientist have done extensive work in monitoring the background radiation of various localities in recent time in Nigeria. The sub-industrial area of Port Harcourt background radiation measurement was carried by Avwiri and Ebeniro (2002). Nwankwo and Akoshile (2005) monitor external background radiation level in Asa industrial layout of Ilorin, Kware State. Farai and Vincent (2006) carried out measurement of outdoor radiation level Abeokuta, Nigeria. The purpose of this article is to provide a documented baseline natural radiation level measurement for Iuleha clan in OwanWest local government area, Edo State, Nigeria.

\section{MATERIALS AND METHODS}

Study Area: The study area is shown in figure 1, which is the Geographical map of Owan-west Local government area.

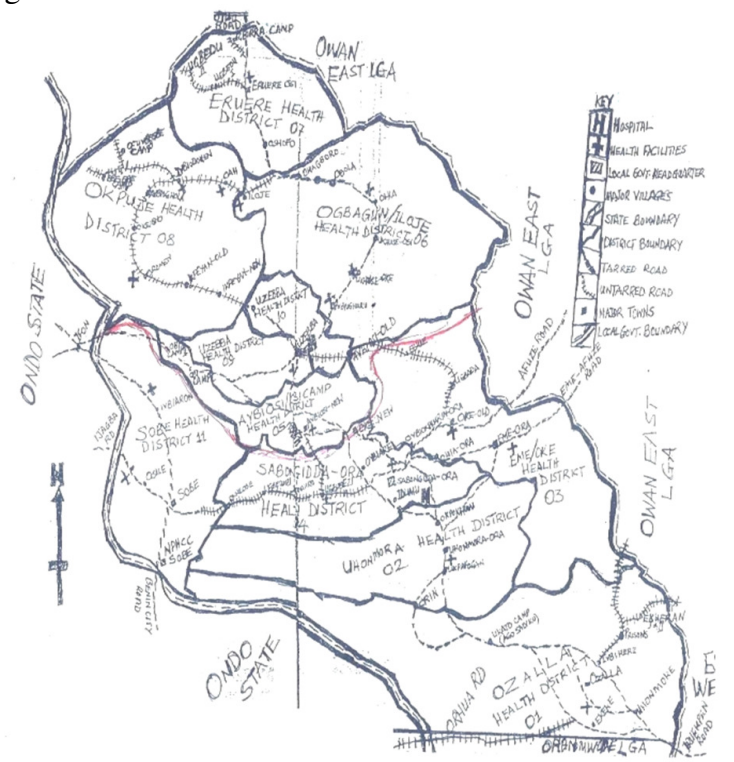

Fig 1: Map of Owan-west Local Government Area with Iuleha shown (Owan-West Orban and regional planning Department, 1992).

Experimental Procedure: In-situ measurement of the background radiation were made with Digilert 50, 
nuclear radiation monitor and a stop watch (Nworgu and Bamidele, 2011). The measurement were taken at every minute interval for 65 successive readings per site. Eighteen sites were selected with adequate coverage in mind.

\section{RESULTS AND DISCUSSION}

Results obtained represent the background radiation level of eighteen sites. Fig 2 is the plot of the radiation $\mathrm{Cph}$ measurement against the various site. At about the centre of sites D, E, F, G, H, P, Q and R is a Quarry.

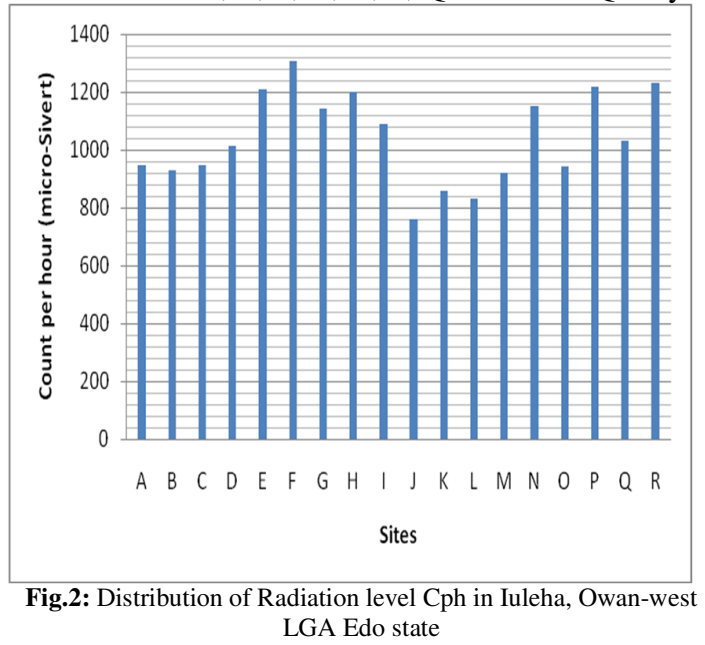

These high radiation counts suggest the presence of granite deposits in the area. Baseline natural radiation level of luleha clan in Owan-West was measured with the aid of Digilert 50 Radiation Monitor. The radiation count per hour ranged from $848 \mu \mathrm{Sv} / \mathrm{hr}$ to 1308 $\mu \mathrm{Sv} / \mathrm{hr}$. Radiation level of sites close to granite deposite (Quarry) were higher. This is likely due to the uranium content of granite structure (Nworgu and Bamidele, 2011).

\section{REFERENCES}

Avwiri, GO; Ebeniro, JO (2002): A Survey of the Background Radiation Levels of the SubIndustrial Areas of Port-Harcourt. Global J. Pure. Appl. Sci. 111-113.
Daryoush Shahbazi-Gahrouei; Mehrdad Gholami; Samaneh Setayandeh. (2013): A review on natural background radiation. Advanced Biomedical Research. .2. 65 - 71 .

Farai, IP; Jibiri, NN (2000): Baseline Studies of Terrestrial Outdoor Gamma Dose Rate Levels in Nigeria. Radiat. Prot. Dosim. 88(3): 247-254.

Farai, IP; Vincent, UE (2006): Outdoor Radiation Level Measurement in Abeokuta, Nigeria, by Thermoluminescent Dosimetry. Nig. J. Phys; 18(1): 121-126.

Gogolak, CW; Winkelman, W S; Wolf, S; Klopfe, p. (1986): Observation of Chernobyl Fallout in 1CRP (1991): Recommendations of the International Commission on Radiological Protection. Annals of ICRP 194 (46).

IAEA, (1988): International Atomixed Energy Agency. The Radiological Accident in Goiania STI/PUB/815/Vienna: IAEA.

Nwakwo, LI; Akoshile, OO (2005): Monitoring of External Background Radiation Level in Asa Dam Industrial Area of llorin, Kwara State, Nigeria. J. Appli. Sd. Eviron Mgt. 9(3): 91-94.

Nworgu, OD; Bamidele, L (2011): Outdoor Ionizing radiation level in Esa-oke, South-western Nigeria. Nig. J. Physics. 22(1) pp $100-105$.

NCRP. (1976): Report No. 050 - Environmental Radiation Measurements.

Obed, RI; Farai, IP; Jibiri N.N (2005): Population Dose Distribution Due to Soil Radioactivity Concentration Levels in 18 Cities across Nig. J. Radiol. Prot. 25: 305-312

Odunaike, RK; Ozebo, VC; Alausa, SK.; Alausa LM. (2008): Radiation Exposure to Workers and Villagers in and Around Some Quarry sites in Ogun State of Nigeria. Environ. Res J. 2(6): 348 -350 . 